\title{
The Concept of the Relative Adjective
}

\section{Svetlana Vinogradova}

This article aims to give a cognitive linguistic account of the dual nature of the concept of relative adjectives, and the specific character of their semantic processes. After a brief discussion of the adjectival character of the relative subclass, it will be argued that denominal relative adjectives belong to the class of predicate words (i.e., words denoting property and hence forming a predicate concept), while retaining, on the other hand, the substantive nature of the basic noun's concept. Further, two subclasses of relative adjectives are contrasted in view of their cognitive processes: substancepredicate, denoting a certain substance of which an object is made, and argumentpredicate, denoting an object the relation to which becomes a property of another object. The substance-predicate group of relative adjectives will be analyzed as having the properties of qualitative adjectives, as they clarify their meanings in discourse due to the operation of profiling the landmark properties on the base of the trajector of the described object. On the other hand, the conceptual entity of argument-predicate relative adjectives can be described by means of the theory of conceptual integration. Argument-predicate adjectives in discourse form a new conceptual blend that is the result of mapping the mental spaces of the predicate concept and the concept of the described noun. The relation between the two objects that appears in the blend forms the context meaning of the adjective.

\section{Keywords}

Adjective; concept; semantics; cognitive process; conceptual integration; mental spaces; profiling

\section{Introduction}

The purpose of this article is to discuss relative adjectives, the dual nature of their semantics, and the specific character of their concepts. Denominal relative adjectives, as well as verbs, adverbs, etc., belong to the class of "predicate words" ("predikatnye slova/priznakovye slova" - the term commonly used in Russian linguistics to refer to all groups of words capable of denoting properties, i.e., denoting some quality or action; see, among others: Nikitin 
598, Susov 210). Due to their semantics, attributive syntactic function and part-of-speech meaning predicate words are opposed to substantive words like nouns which denote entities. Therefore, they form a predicate concept, while retaining, on the other hand, the substantive nature of the basic noun's concept. Hence the peculiarities of their conceptual procedures: the conceptual entity of relative adjectives is described by means of the theory of conceptual integration. In discourse, many relative adjectives form a new concept that is the result of mapping the mental spaces of the concept of the relative adjective and the concept of the described noun. In contrast to the relative adjectives, the qualitative adjectives profile (i.e., make prominent, salient) one of the properties of the described noun without integration of concepts (blending). This specificity of the relative adjectives is based on their morphological character, their belonging to a certain morphological class and subclass. Therefore, this article focuses on such type of concepts that are expressed morphologically.

Morphology provides a conceptual grid, a framework for the conceptual material expressed lexically. Lexical categories are analogical to those of the surrounding world, and their structure, for that reason, manifests an analogy to the categories of natural objects, which, in turn, suggests that their structure is logical in character. Grammatical categories, for their part, are linguistic categories and reflect the ontology of the language, serving, as they do, as its natural categories, i.e., as the categories of natural objects. Part-of-speech categorization brings to the fore the categorical meanings of the parts of speech, making it evident that "the entire nominative space of the noun reflects the cognition of objects and substances as participants in certain types of activity, while the space of verbal lexis is a space related to movement existing and unfolding itself in the flow of time, a space of relations and events, or that of actions involving certain actors, or states of affairs" (Kubrjakova 210).

Morphological categories are known to be of three types:

1. associated with expressing predication, focused on expressing the meanings which exceed the proposition;

2. representing the ways connections between the real-world objects are reflected in the language - the level of propositional relations, correlated with the predicate (the verbal categories of number, voice, aspect);

3. representing the semantic level of linguistic units proper, i.e., the semantics oriented towards the outer world. The latter are focused on mapping 
the relations conveyed by the first two types of categories, on their systematization. In this case we are talking about such categories as abstract/concrete, terminative/nonterminative, qualitative/relative and the directly related nominal morphological categories of number, case, and degrees of comparison (Besedina 153).

These types of categories are based on the structurally different concepts expressed morphologically. This is due to the fact that morphologically expressed concepts, representing as they do the components of the complex structured knowledge, correlate, on the one hand, with a verbalized part of the conceptual system in the human mind, and on the other - through verbal concepts - with the extralinguistic world. Categories of the first two types are based on the concepts that reflect both the ontology of the world, and the ontology of the language. The concepts underlying the morphological categories of the third type form part of the actual language skills, emphasizing the relationship of humans with the world of language. They assume knowledge of general concepts and methods of their representation in the language and therefore are less complex in structure.

\section{The Place of Relative Adjectives in the Morphological Class of Adjectives}

With most Russian grammarians, it has long been a thoroughly traditional approach to divide adjectives into two main classes: qualitative and relative. Qualitative adjectives, being "model, i.e., central" adjectives, convey the idea of a certain autonomous property directly and have a predicate function ("a red dress", "a round table", "a pleasant voice"), while relative adjectives denote a property via the idea of an object bearing this property ("starry configuration" - a configuration of stars, "crystalline structure" - a structure of a crystal, "crystalline waters of the lake" - clear - like crystal - waters of the lake). Relative adjectives are derived from other parts of speech (nouns, verbs, etc.) and retain in their semantics a semantic mould of the basic word. The difference is supported grammatically (relative adjectives do not build the forms of degrees of comparison, do not take the predicative syntactic function in a sentence, and - in the Russian language - do not build short forms. The 
part-of-speech classification, as well as the division into subclasses, being an object of morphology, are of prime importance for the study of the semantics of adjectives.

If we adhere to the definition of the adjective as a word denoting properties and one which is grammatically specified in a predicate (though syntactically attributive and predicative) function, we will have to concede that relative adjectives do not pertain to this class for a number of reasons. They are in fact considered by many linguists to be defective adjectives, pseudo-adjectives, as they do not convey the idea of property, but mostly the idea of a subject (notion) denoted by the basic noun (Postal, Bartning). Similarly, they are also described as mimicry forms of nouns (Rudelev 133), "nonadjectival adjectives" (Carlsson), "nominal objects" (Grammaire Larousse), etc. Their only adjectival feature, according to this school of thought, is their attributive syntactic function. It has not been uncommon, either, for linguists to consider them to be equal to noun+noun constructions (Levi). Even the prominent Russian linguist Academician Viktor Vinogradov, defining quality rather unequivocally as the "semantic foundation of adjectives", eventually finds himself unable to resist the seemingly inevitable temptation to deprive relative ones of their functional specificity and maintains that rather than a quality, relative adjectives denote subject relations, and that they are synonymic substitutes for attributes realized by nouns and adverbs (Vinogradov 176).

It must be admitted that even the author of this article herself, when studying the semantic derivation of relative adjectives in the framework of formal semantics, referred them to the substantive class (Vinogradova, "Reflection"). This conclusion was made for the reason that the semantic structures of derived adjectives had been found to contain semes inherited from the semantics of the basic nouns. It was mentioned, though, that it is their adjectival semantics that enables them to realize the latent possibilities of their nominal bases. At the same time, the study of denotative-significative status of adjectives, well-discussed in semantics, has resulted in a description of adjectives either as not possessing their own denotatum (while describing the denotatum of the determiner and being a significatum) or, when used in isolation, in vocabulary, as possessing a denotatum - the idea of a certain abstract quality. The nature of relative adjectives, defined as always possessing their denotata, has given some researchers what they find to be firm grounds for considering them subject words in contrast to qualitative adjectives treated as predicate words (Nikitin; Vinogradova). 
It comes as no surprise, therefore, that, for all their difference in semantic value and derivational character, the two subclasses of adjectives have much in common that brings them together into the same class, and it is the cognitive approach that shows the possibility of treating them jointly. The cognitive approach to the grammatical category treats it as a prototypical category. It is based on the idea of a representative sample around which natural categories are formed. The members of the category, then, become elements that have similarities to the prototype (the presence of prototypical characteristics), the number and composition of which can be graded from more to less; the category boundaries become uncertain, fuzzy, and there may be transition zones between adjacent categories. The category of adjectives is often perceived through the subcategory of qualitative adjectives which has come to stand metonymically for the entire class. However, alongside prototypical elements, those that exhibit different proportion of typical features, there are also other equal members in the category. The prototypical character of the category makes it possible to consider relative and qualitative adjectives to be equal members of the category on the basis of their semantic value of property.

The controversial nature of relative adjectives has its roots in the historical evolution of the class of adjectives which is believed to have derived from the originally unified category of name. At first, each adjective reflected the semantics of the basic noun. Ronald Wayne Langacker (Cognitive 61) describes this feature as analyzability. He remarks that the explicity of the semantic structure is one of the dimensions of imagery which provides a greater cognitive salience of the word. According to Langacker, analyzability tends to be increasingly erased as the units of the language become fixed, but even if the speakers of the language cease to be aware of analyzability, there remains some level of information at which the relevant substructures may still be activated (cf.: "computer" from "compute", "propeller" from "propel", etc.) (Langacker, Cognitive 61). The same process can be observed when analyzing the denominal adjectives like "violet" - from "violet", "orange" from "orange", "chestnut" from "chestnut" and "lime" from "lime".

At some later stage, the adjectives were abstracted from the application of the property to a certain object and became the bearers of an autonomous property. Relative adjectives today illustrate this continuing tendency and are the source of replenishment of the class. Their tendency of turning into qualitative adjectives has been given considerable attention by linguists past and present. The reason for this re-categorization has been described as possessing a cognitive basis, fixing in the word the result of the cognition 
of the world. The relatively late arrival of psychological cognition, of the cognition of the inner side of the human being, has guided the transition of relative adjectives into qualitative ones: "husky" - hoarse voice, "reedy" - shrill voice, "silvery" - clear voice, laugh, chime, etc. (COHA). "Volcanic" - of or pertaining to a volcano or volcanoes, "a volcanic eruption"; discharged from or produced by volcanoes, "volcanic mud"; suggestive of or resembling a volcano; potentially explosive; volatile: "a volcanic temper" (SOD).

Hence, relative adjectives may be considered the result of transcategorization. Generally speaking, in the process of transcategorization, the transition of grammatical meaning into a semantically dependent subordinate element takes place for the purpose of its salience (cf.: red - redness, move - movement). The word acquires a new meaning precisely as a result of a transposition of the original word into another part of speech. This process may be said to pertain also to the relative adjectives. As was mentioned above, the relative adjective is the result of part-of-speech transcategorization, the result of the transposition of a noun into the class of denominal adjectives.

The cognitive processes involved in this transposition have been extensively studied in the framework of the cognitive semantics of derivatives. During the transposition, the newly-coined adjective, compared to its attributive noun equivalent, acquires a predicating nature that shows itself in the processes of metaphorization of latent properties. For instance, the adjective "airy" - light, lightweight - unfolds a latent property of the object: air. The process goes on further: "airy" - light - graceful, "airy tread"; "airy" - light - careless, cheerful, merry, "airy laughter", "airy" - light - empty, giddy, flyaway, "airy promise", "airy" - aerial, ethereal, unreal, "airy notions" (SOD). Such meanings are not realized in the usage of the noun in an attributive syntactic function. For instance, the noun "spike" has the meaning of sharpness which leads to the appearance of " $a$ spike of light", but it is never used in the meaning of "cantankerous, quarrelsome, grumpy", as the adjective "spiky" is ("a spiky dog", "a spiky churchman") (SOD). Their predicate nature enables the adjectives to realize the latent possibilities of the basic noun (Vinogradova).

The predicate character of the relative adjective presupposes the presence of such a component in its meaning that distinguishes it from the corresponding noun used attributively. This is an essential property of its concept which is formed through conceptual derivation from the concept actualized by the basic noun. In the new concept, the properties that become the basis of metaphorization are made salient, they are profiled on the basis of the new 
unaccustomed usage: "airy room" - "airy behaviour". The concept of the relative adjective is built in such a way that in discourse metonymical, metaphorical and other ways of functioning are realized, which fail to be so in the case of their attributive-nominative analogues: equivalent attributive nouns generally do not develop such secondary meanings.

Returning to the issue of the status of the relative adjectives, let it be noted that though they keep in their semantics the semantic mould of the basic noun, they should be considered primarily as belonging to a common lexical-semantic category of adjectives. Their predicate semantics is obvious in the semantic processes described: i.e., in the ability to realize the latent properties of the basic nouns in metaphoric and metonymic meanings. It would be inappropriate to disregard their part-of-speech character which affects the functioning of the relative adjective in speech and the formation of the corresponding concept.

\section{The Concept of the Adjective: Qualitative vs. Relative}

Speaking of the adjective generally, the following peculiarities deserve to be emphasized: an adjective gives us access to the concept that is in our mind either in the form of a sensory image (e.g., that of colour, taste, or one conveying the form of an object or its size, etc.): red, round, sweet, warm, or in the form of an abstract rational property, i.e., one rationally substantiated in the mind: pyramidal, oval, etc. More often than not, this concept is formed on the propositional pattern: an argument and its predicate, in this case, a property. The part-of-speech cognitive characteristic of the concept of the adjective is its predicativity, the ability to denote (and ascribe) a property, which is in one way or another expressed in various languages through part-of-speech affixes, the place in a sentence or word combination, in an attributive chain, through the presence of certain morphological characteristics like degrees of comparison, or, in the Russian language, - the availability of the "short form", etc. But predicativity is not characteristic of the adjectival concept only: words denoting objects, or even situations, may be used in an attributive function. This object must contain properties that could be highlighted for the description of another object or situation. The idea of a quality may be actualized, i.e., foregrounded, by actualizing in the mind a property of the basic level (represented by such adjectives as red, round), 
or through the actualization of another concept containing this cognitive property in its structure. In this case a certain property of the concept is salient in this particular speech representation: starry night, tropical heat, stony fruit.

By assuming the predicate character of all adjectives, we recognize the ability of them all, including relative adjectives, to actualize a predicate concept in the mind. But when doing so, we should remember the prototypical organization of this category. Qualitative adjectives may be said to form the prototypical component of the category, as it is the qualitative property that would appear to have a primary perceptive basis, as well as belonging mostly to the cognitive domain of the basic level. The relative property has a more complicated structure. In this case, the formation of a concept takes more time, and requires the participation of the rational powers, which leads to the appearance of a construct in the mind. Neither should it be overlooked that the derivational character of the relative adjective enables it to refer back to the original word (and the original concept), to contain a signal, a hint to everything that is connected with the natural environment of this word, its notion, and the underlying reality.

As any derivative preserves in its semantics the semantic mould of the original word, a relative adjective refers us back to the concept that is actualized by the basic noun, evoking in the mind those cognitive signs which are relevant for this linguistic usage. This conceptual sign (or signs) is (are) salient for the formation of a new concept of the adjective (e.g., flowery odour - like that of a flower, starchy - containing starch grains, etc.)

\section{The Argument-Predicate and Substance-Predicate Relative Adjectives}

Moreover, relative adjectives are a heterogeneous class. This point is very well illustrated by the division of relative adjectives, suggested by Mihail V. Nikitin (Nikitin) into substance-predicate adjectives (where the substance of which the denotatum is made becomes its property, as in "wooden table", "sandy beach", "crystalline cup") and argument-predicate adjectives (where the property of the denotatum is its relation to another denotatum, as in "oceanic winds", "tropical fruit", "governmental law"). In the latter case, evoking the idea of the property in the mind requires that the encyclopaedic knowledge of the world and the relations of the denoted objects should be actualized/activated. 
Substance-predicate adjectives, though also being noun-derivatives, are closer in their pattern to qualitative adjectives, since their concepts emerge as sensory images of integral concepts ("a wooden table", "a woolen sock", "sugary water") and attain the level of rational concepts through abstraction. The speakers' encyclopaedic knowledge gives them an idea of the origin of the material, as well as its name, but when used in speech, the adjective and its noun form an integral image. Highlighting the property (quality) of an object, interpreting it as a separate property applicable to other objects becomes possible on further consideration.

Argument-predicate adjectives are more closely bound to the basic concept represented in speech by the noun from which they derive. When used separately, such a word cannot give access to the predicate concept. As is commonly understood in cognitive grammar (emergent grammar, discourse grammar studies, usage-based approach, construction grammar, etc.), linguistic forms should be regarded as devoid of categorical certainty unless it is forced on them through their discourse functions. They need to be specified in discourse, if they are to evoke in the mind a complex concept, and for this purpose complex cognitive interpretational procedures have to be engaged.

The cognitive property that such adjectives contain reminds the speakers that the word used should refer the mind to the original concept and redirect its constituents in relation to the described concept. It is at the intersection of these concepts that the described entity appears. This may be an integral concept as in "stellar configuration" or "musical sound", a complex concept as in "agricultural work", "educational system", a frame-concept as in "academic knowledge", "scientific approach", or a script like "musical comedy", "social revolution". Therefore, to describe the conceptual entity of substance-predicate relative adjectives, Langacker's idea of salience should be taken into account. At the same time, argument-predicate adjectives in discourse, describing, as they do, a certain noun (object-concept), form a new concept that is the result of mapping the mental spaces (Fauconnier) of the predicate concept and the concept of the described noun. 


\section{Langacker's Construal Operations Used for the Formation of the Discourse Meaning of the Relative Adjectives}

Coming back to Ronald Wayne Langacker's ideas, we should emphasize the following: using the metaphor of visual perception, Langacker (Cognitive 55) compares the construal of a particular conceptual content to the viewing of a scene (see above) and divides this process into four major steps: "In viewing a scene, what we actually see depends on how closely we examine it, what we choose to look at, which elements we pay most attention to, and where we view it from" (Langacker, Cognitive 55). Accordingly, he distinguishes between the following four major construal operations: specificity, focusing, prominence and perspective. Specificity refers to "the level of precision and detail at which a situation is characterised" (Langacker, Cognitive 55). Focusing involves "the selection of conceptual content for linguistic presentation, as well as its arrangement into [...] foreground vs. background" (Langacker, Cognitive 57, boldface removed). Prominence is concerned with the relative saliency of various aspects of a structure foregrounded in the process of focusing (Langacker, Cognitive 66). Perspective describes the vantage point from which a given scene is viewed (Langacker, Cognitive 73).

The construal operation of specificity is relevant to the analysis of the meaning of the relational adjectives only in the case of the explicational combinations of the relative adjective with the described noun. These are combinations like "bodily movement", "solar radiation", "muscular pain" that are formed as a rule as attributive transforms of the predicate structures "body moves", "the sun radiates", "muscle(s) hurt(s)", where the relations between the two concepts are explicit. In this case there is no need to complete the mental construction of the meaning; the construing only shows that more attention is paid to the thought of the action as an epistemic subject, while the relative adjective is a transform of the concept, although it is less salient.

Obviously, it is the construal operation of focusing that is of special interest to the present article, since it is concerned with the lexical meaning of the relative adjectives of the second type: building an elisional word combination with the described noun. This means that the meaning of the adjective requires completion of mental construing by explication of their implicit relations: woolen goods - goods < made of > wool, woolen company - company < that deals in> wool (woolen goods), woolen pile - a pile <consisting of > wool, woolen socks - socks <knitted of $>$ wool, etc. (examples from COHA). In this case the 
meaning of the relative adjectives is the relation that appears between the concepts of the basic noun and the described noun.

For studying lexical meaning it is necessary to refer to the idea of a cognitive context - cognitive structures, or blocks of knowledge, that lie behind these meanings and provide for their understanding. Such cognitive contexts are variously called "semantic frames" (Fillmore), "domains" (Taylor), "mental spaces" (Fauconnier; Lakoff), etc. A semantic frame is defined as a knowledge structure that is required in order to understand a particular word or a related set of words (Evans 192). In the same vein, a domain is defined as "any knowledge configuration which provides the context for the conceptualization of a semantic unit" (Taylor 196). The function of frames and domains is thus to provide background information which serves as the basis for understanding and using lexical concepts (Evans and Green 230). According to Evans and Green (166-167), the profile of a linguistic unit is that part of its semantic structure upon which the linguistic unit focuses attention. The profile would thus be that part of the semantic structure that is explicitly mentioned. The base, on the other hand, is the essential part of the conceptual or domain matrix that is necessary for understanding the profiled entity (Evans and Green 237).

The semantic analysis of a linguistic expression presupposes a reference to its cognitive domain, but it may, in its turn, refer to another cognitive domain (arc-circle-space) and so forth, this way conceptual hierarchies are built. The meanings of some linguistic units refer directly to basic domains, like those of qualitative adjectives, denoting the features like manner, amount, direction, sound, smell, time: i.e., "red", "warm". They identify the major ontological categories, and in Langacker's cognitive grammar these features, together with things, actions, places, etc. are called "basic domains". But the majority of linguistic units refer to non-basic domains and then step-by-step goes the reference to the basic domain. Relative adjectives, in contrast to qualitative ones, build their meaning this way: "sandy hair" - the colour of sand - yellow, "spiky lashes" - of the nature of a spike - sharp, "stony silence" - of the weight of a stone - heavy, etc.

Langacker uses the terms "foreground" and "background", as well as "profile" and "baseline" for studying the phenomenon of meaning. In Leonard Talmy's cognitive semantics the mechanism of figure and ground was used for studying sentence structure; Langacker's cognitive theory of language analyzes meaning only on the conceptual level. Figure for Talmy is everything that moves, that is mobile, that comes first into the speaker's sight (like the view 
from the window - cars, people, etc.), the ground is everything that is in the background, that is static. Figure is recognized, is represented in language by a word that occupies the first place in a sentence: Fohn broke the window. The stone broke the window.

In Langacker's terms, a linguistic unit obtains its meaning in the process of overlaying the profile on the base: the "base" being an immediate scope in active domains, the portion put "onstage" and foregrounded; within this onstage region attention is directed to the particular substructure which is called "profile" (Langacker, Cognitive 66). So, all semantic units are characterized by the imposition of the profile on the base. Linguistic units, including adjectives, are treated by Langacker as relational groups. Relational predication profiles the relations between two or more entities. The one that is in the focus and is more salient in this predication is considered a trajector, while the other one, different from the trajector, but also salient, is called a landmark. In linguistic expression adjectives have an object as their trajector (Langacker, Overview 61, 76).

The substance-predicate group of relative adjectives are considered as having the properties of qualitative adjectives, as they clarify their meanings in discourse due to the operation of profiling the landmark properties on the base of the trajector of the described object: "wooden table", "woolen socks", "sugary fruit", "metallic brush", "brassy knob", etc. The process of the further development of their semantics (metaphorically or metonymically) from the point of view of conceptual mechanisms should be studied by itself and will probably include the idea of conceptual integration.

\section{Conceptual Integration in the Meaning Formation of the Argument-Predicate Adjectives}

In a relational group with an argument-predicate relative adjective, trajector and landmark are both objects, and the meaning of the expression profiles the relation that appears during the interaction of the entities. One of the objects is expressed by the described noun, the other one - by the reference to the original noun concept of the relative adjective - i.e., the basic noun concept. The blend, appearing through the interaction of the concepts in the process of conceptual integration, includes the relation that appears in the discourse, as the products of mental construing - mental spaces - differ from cognitive models (cognitive domains) due to their being "models of 
discourse" rather than "models of the world" (Fauconnier). Consequently, integrated mental spaces should be considered as conceptual formations that are built under the influence of context. Mental space is created on the basis of both the information conveyed by the discourse, and the information taken from the conceptual domain (domains) it is closely connected with. Thus, mental spaces can be employed also for the analysis of the meaning of relative adjectives. (Eve Sweetser used the theory of mental spaces integration for the analysis of the group "red ball", and found the possibility of mapping of the mental spaces of the concepts of the adjective and the described noun and forming the blend.)

The theory of conceptual integration supposes that the creation of a new meaning is an active process of establishing various relations between mental spaces, in which integration of different aspects of information takes place. In fact, a creative process is launched in which a person chooses the ways and means of construing the situation or the object. The blending of conceptual entities takes place on the interdimensional level - Gilles Fauconnier and Mark Turner have introduced the notion of an integrated (mixed) space, or blend, which is the result of a fusion of two or more spaces. Integrated spaces, inheriting the roles and features of initial spaces, receive their own structure and properties. They function as indivisible structural wholes and make it possible to reconstruct their connections with the initial mental spaces.

While being a result of cognitive complexity, a blend remains compact and easy to use due to the compression of the substantive relationships between the spaces inside the blend. This compression leads to the extreme flexibility of the integrative processes. For example, let us consider the adjective starry:

She traced the lettering in the starry sky above the beautiful ship with a finger (COHA: 2006).

Sometimes Ray will stop in the woods on a starry night to let his guests soak up the glorious silence (COHA: 2007).

Combinations with the nouns night and sky are among the most frequent, according to the Corpus of Historical American (COHA): the combination "starry sky" has the highest frequency and stands on the first position in the frequency list, "starry night" - on the second. In the phrase "starry night", a sequential unfolding of spaces takes place: "night" - "night sky", as "starry night" means "the night with many stars in the sky". Two mental spaces are formed by the noun "sky" and by the adjective "starry" which in its turn contains the reference to the noun "star". The fusion of the spaces creates a blend in which the relation FULL OF is brought to light. At the same time, from the mental 
space of the star the components "sparkle", "shine", "the source of light at night", "romanticism", etc., are placed in the blend. The blend is convenient, as it compresses the information of both spaces into an integer that is easy to use.

Profiling crucially figures in the pervasive phenomenon known as metonymy. In a narrow sense, we can characterize metonymy as a shift in profile. We speak of metonymy when an expression that ordinarily profiles one entity is used instead to profile another entity associated with it in some domain. Profiling as a cognitive operation is a medium to study the regular source of polysemy, the source of which is metonymy. In other words, metonymy is a blend that arises from the fusion of two spaces, the combination of which is explained in terms of cause-result, product-producer, whole-part, etc. relations. In the case of relative adjectives, it can be illustrated as: "bilious complexion" - yellow, greenish (as a result of excessive bile secret). Further, metaphorical usage can be seen. Sweetser uses the idea of mental spaces for the study of cognitive processes of semantic derivation. She maintains that the progression of the semantic evolution of the word is unidirectional: from an external (sociophysical) domain to an internal (emotional, psychological) domain, i.e., from a specifically-aimed to an abstract-aimed domain. Metaphor is understood as a shift in which the properties of one concept are transferred to another, giving us a possibility to cognize one domain (target) in terms of another domain (source).

\section{Conclusion}

Thus, having examined the cognitive properties of the relative adjectives we come to the conclusion that since the part-of-speech category exhibits a prototypical character, relative adjectives are included in the category of adjectives as equal members, having a predicate nature that is revealed in semantic derivation. Secondly, adjectives clarify their meanings in the discourse due to the emphasizing (prominence, salience) of the property of the landmark, i.e., due to the operation of profiling against the background of the base (trajector) of the described object. This pattern, however, is not followed by relative adjectives, which, due to their derivational character, bear in their semantic structure the mould of the meaning of the basic noun. Hence, the appearance of the contextual meanings of the relative adjective is explained by the cognitive mechanism of conceptual integration: mental spaces of the 
concept of the relative adjective and the described noun are integrated so that in the blended space the compression of the initial information takes place; the meaning of the relative adjective (argument-predicate in the first place) is the relation between the two objects that appears in the blend; the extension of combinability of the relative adjective gives a possible metonymical meaning, and when describing an exotic, unusual object, relative adjectives develop metaphorical meanings.

Besides, we have to admit, such relative adjectives as substance-predicate adjectives (in contrast to argument-predicate ones) tend to follow the pattern of qualitative adjectives in not creating a blended space in the combination with a noun, but profiling a certain property of the object, making it more prominent. Substance-predicate adjectives are characterized by a sequential unfolding of cognitive domains, the result of which is a reference to the basic cognitive domain.

So, the mechanism of profiling a certain property of an object is shared by qualitative adjectives and those relative adjectives which are called substancepredicate, while argument-predicate relative adjectives form their meaning by the cognitive mechanism of conceptual integration of mental spaces of the concept of the relative adjective and the described noun.

\section{Works Cited}

Bartning, Inge. Remarques sur la syntaxe et la sémantique des pseudo-adjectifs dénominaux en français. Stockholm: Almqvist \& Wiksell international, 1980. Print.

Besedina, Natal'ja A. "Konceptual'noe prostranstvo morfologii." ("Conceptual Space of Morphology") Konceptual'noe prostranstvo jazyka. (Conceptual Space of the Language.). Tambov: Izdatel'stvo Tambovskogo gosudarstvennogo universiteta imeni G.R. Derzhavina, 2005. Print.

Carlsson, Lennart. Le degré de cohésion des groupes subst.+de+subst. en français contemporain, étudié d'après la place accordée à l'adjectif épithète. Uppsala: Almquist \& Wiksell, 1966 (Studia Romanica Upsaliensia, Band 3). Print. Fillmore, Charles, J. The Case for Case. Universals in Linguistic Theory. Ed. by E. Bach and R. Harms, 1-88. New York: Holt Rinehart and Winston, 1968. Print.

Evans, Vyvyan. A Glossary of Cognitive Linguistics. Edinburgh: Edinburgh University Press, 2007. Print.

Evans, Vyvyan and Melanie Green. Cognitive Linguistics. An Introduction. Edinburgh: Edinburgh University Press, 2006. Print. 
Fauconnier, Gilles. Mental Spaces: Aspects of Meaning Construction in Natural Language. Cambridge: Cambridge University Press, 1994. Print.

Fauconnier, Gilles and Mark Turner. The Way We Think. Conceptual Blending and the Mind's Hidden Complexities. New York: Basic Books, 2002. Print.

Grammaire Larousse XXe Siécle. Félix Gaiffe, Ernest Maille. Paris: Libr. Larousse, 1936. Print.

Kubrjakova, Elena. Chasti rechi s kognitionoj tochki zrenija. (Parts of Speech in Cognitive Perspective). Moskva: Institut jazykoznanija RAN, 1997. Print.

Lakoff, George. Women, Fire, and Dangerous Things. What Categories Reveal about the Mind. Chicago: The University of Chicago Press, 1987. Print.

Langacker, Ronald Wayne. Cognitive Grammar. A Basic Introduction. Oxford: Oxford University Press, 2008. Print.

---. "An Overview of Cognitive Grammar." B. Rudzka-Ostyn (ed.). Topics in Cognitive Linguistics. Amsterdam; Philadelphia: John Benjamins Publishing Company, 1988. Print.

Levi, Judith N. The Syntax and Semantics of Complex Nominals. N.Y.: Academic Press Inc., 1978. Print.

Nikitin, Mihail V. Kurs lingvisticheskoj semantiki. (A Course of Cognitive Semantics): Uchebnoe posobie. Sankt-Peterburg: Izdatel'stvo Rossiyskogo gosudarstvennogo universiteta imeni A.I. Gercena, 2007. Print.

Postal, Paul. The Derivation of English Pseudo-adjectives. Unpublished Manuscript, Thomas J. Watson Research Center, IBM (Yorktown Heights High, N.Y.), 1972. Print.

Rudelev, Vladimir G. "Mimikrija v sisteme chastej rechi russkogo jazyka." ("Mimicry in the System of Parts of Speech of the Russian Language.") Konceptual'noe prostranstvo jazyka. (Conceptual space of the language.) Tambov: Izdatel'stvovo Tambovskogo gosudarstvennogo universiteta imeni G.R. Derzhavina, 2005. Print.

Susov, Ivan P. Vvedenie v jazykoznanie. (Introduction into Linguistics). Moskva: AST: Vostok-Zapad, 2006. Print.

Sweetser, Eve. From Etymology to Pragmatics. Cambridge: Cambridge University Press, 1990. Print.

Talmy, Leonard. Toward a Cognitive Semantics. Vol. 1: Concept Structuring systems. Cambridge: MIT Press, 2000. Print.

Taylor, John R. Cognitive Grammar. Oxford: Oxford University Press, 2002. Print. 
Vinogradov, Viktor Vladimirovich. Russkij jazyk: (Grammat. uchenie o slove). (The Russian Language: Grammatical Teaching of the Word): [Ucheb. posobie dlja vyssh. ucheb. zavedenij]. Moskva, Leningrad: Uchpedgiz, 1947. Print.

Vinogradova, Svetlana A. Otnositelnye prilagatel'nye v kognitivno-semanticheskom aspecte. (Relative Adjectives in the Cognitive-Semantic Perspective). Murmansk: Murmanskij gosudarstvennyj gumanitarnyj universitet, 2012.

COHA - The Corpus of Historical American English [COHA] Brigham Young University, n.d. Web. 3 January 2014.

SOD - The New Shorter Oxford Dictionary on Historical Principles, Ed. by Lesley Brown [SOD]. Oxford: Clarendon Press, 1993. Print. 